\title{
BMJ Open Patient and parent perspectives on transition from paediatric to adult healthcare in rheumatic diseases: an interview study
}

Ivy Jiang (D) ,1,2,3 Gabor Major, ${ }^{4,5}$ Davinder Singh-Grewal, ${ }^{6,7}$ Claris Teng, ${ }^{1,2}$ Ayano Kelly (D) , ${ }^{8,9}$ Fiona Niddrie, ${ }^{4}$ Jeffrey Chaitow, ${ }^{4,7}$ Sean O’Neill, ${ }^{6,10}$ Geraldine Hassett, ${ }^{6,10}$ Arvin Damodaran,, ${ }^{311}$ Sarah Bernays, ${ }^{12,13}$ Karine Manera (D) , ${ }^{1,2}$ Allison Tong, ${ }^{1}$ David J Tunnicliffe ${ }^{2,14}$

To cite: Jiang I, Major G, Singh-Grewal D, et al. Patient and parent perspectives on transition from paediatric to adult healthcare in rheumatic diseases: an interview study. BMJ Open 2021;11:e039670. doi:10.1136/ bmjopen-2020-039670

- Prepublication history and additional materials for this paper are available online. To view these files, please visit the journal online (http://dx.doi. org/10.1136/bmjopen-2020039670).

Received 23 April 2020

Revised 22 November 2020

Accepted 16 December 2020

D Check for updates

(C) Author(s) (or their employer(s)) 2021. Re-use permitted under CC BY-NC. No commercial re-use. See rights and permissions. Published by BMJ.

For numbered affiliations see end of article.

\section{Correspondence to} Dr David J Tunnicliffe; david.tunnicliffe@health.nsw. gov.au

\section{ABSTRACT}

Objectives To describe the experiences, priorities, and needs of patients with rheumatic disease and their parents during transition from paediatric to adult healthcare.

Setting Face-to-face and telephone semistructured interviews were conducted from December 2018 to September 2019 recruited from five hospital centres in Australia.

Participants Fourteen young people and 16 parents were interviewed. Young people were included if they were English speaking, aged 14-25 years, diagnosed with an inflammatory rheumatic disease (eg, juvenile idiopathic arthritis, juvenile dermatomyositis, systemic lupus erythematosus, panniculitis, familial Mediterranean fever) before 18 years of age. Young people were not included if they were diagnosed in the adult setting.

Results We identified four themes with respective subthemes: avoid repeat of past disruption (maintain disease stability, preserve adjusted personal goals, protect social inclusion); encounter a daunting adult environment (serious and sombre mood, discredited and isolated identity, fear of a rigid system); establish therapeutic alliances with adult rheumatology providers (relinquish a trusting relationship, seek person-focused care, redefine personal-professional boundaries, reassurance of alternative medical supports, transferred trust to adult doctor) and negotiate patient autonomy (confidence in formerly gained independence, alleviate burden on patients, mediate parental anxiety).

Conclusions During transition, patients want to maintain disease stability, develop a relationship with their adult provider centralised on personal goals and access support networks. Strategies to comprehensively communicate information between providers, support self-management, and negotiate individualised goals for independence during transition planning may improve satisfaction, and health and treatment outcomes.

\section{BACKGROUND}

Young people diagnosed during childhood with rheumatic disease have an increased risk of mortality and morbidities, including
Strengths and limitations of this study

- This study's design is a strength: using purposeful sampling provided a broad range of demographics, geographical regions, and experiences from before, during and after transfer.

- Thematic saturation was reached, which was also a strength of this study.

- Young people and their parents with a range of rheumatic diseases were interviewed, allowing for insight into a specialty where there is increasing interest and research in optimising transitional care for life-long disease that extends into adulthood.

- However, we were limited in our inclusion to Englishspeaking participants in Australia, which may limit the transferability.

early-onset cardiovascular disease, low bone mineral density and infertility compared with the general population. ${ }^{1}$ Adolescents are at a greater risk of active disease flares and have higher rates of hospital readmissions. ${ }^{23}$ They report high levels of pain intensity, functional disability, and rates of psychiatric disorders such as depression and anxiety. ${ }^{4}$ Despite the ongoing impacts through to adulthood, up to half of patients who transition to adult care are lost to follow-up within 2 years after transfer. ${ }^{12}$

Transitional care is the active, planned process of addressing medical, psychosocial, educational and vocational needs of young people preparing for the adult healthcare system. ${ }^{6}$ However, transition remains a clinical challenge because the specific requirements for adolescents and young adults may remain under-recognised, such as reported low confidence in self-advocacy and reluctance to leave trusted paediatric staff. ${ }^{7-9}$ Parental caregivers also have to adapt to 
changes in the young people's needs for independence and autonomy. ${ }^{910}$ Unmet training needs in both paediatrics and adult specialists perpetuates the clinical challenge of transitional care. ${ }^{11}{ }^{12}$ Forty-five per cent of adult rheumatologists reported no transitional care training in recent data from the USA. ${ }^{11}$

The Bridges Transitions Framework assists individuals and organisations in managing change. ${ }^{13}$ The theory delineates between the term 'change', describing the event-based, external situation, and 'transition' considered as the individual's emotional or internal process in response to that change. The three phases of transition described were (1) endings-to identify what must be relinquished; (2) neutral-zone-the in-between period of accepting endings but discomfort with the new, possibly associated with confusion and distress; and (3) new beginnings-focus on the progress and growth towards new values or attitudes, but with possible underlying anxiety about regressing to past phases. Successful coping in the context of transitional care in rheumatology can therefore be facilitated by addressing each of these theoretical phases when targeting patient needs before, during and after the transfer of care.

Previous studies extensively examined the transition perspectives of young people, either in specific rheumatological diseases such as juvenile idiopathic arthritis (JIA) ${ }^{14-18}$ or a broad range of long-term physical or psychological health conditions. ${ }^{19-21}$ However, few studies focus on rheumatological diseases as a key area, in regard to the needs and perspectives of young people. Parent priorities described are similar across a range of health conditions; as needing clarification and support for their roles by transition services and feeling supported by wellcoordinated communication between teams. ${ }^{22}{ }^{23}$ Whether there are slight nuances in transition needs for parents of young people with rheumatological disease across the transfer continuum remains uncertain. ${ }^{14-1824-27}$ This study aims to describe the experiences, priorities, and needs of young people with rheumatic disease and their primary carers on transition from paediatric to adult care. The insights gained will inform ways to optimise transition for improved patient and caregiver satisfaction, access to care and life-participation outcomes.

\section{METHODS}

We applied the Consolidated criteria for Reporting Qualitative research to report this study (see Research Checklist). ${ }^{28}$

\section{Participant selection and setting}

Patients were eligible if they were English speaking, aged 14-25 years, diagnosed with an inflammatory rheumatic disease (eg, JIA, juvenile dermatomyositis, systemic lupus erythematosus (SLE), panniculitis, familial Mediterranean fever) before 18 years of age and their parents. Young people were included only if they had experience with paediatric rheumatology in the public or private setting and were not included if they were diagnosed in the adult setting. Participants were purposively sampled to include a broad range of demographics including, age, sex and type of rheumatic disease. ${ }^{29}{ }^{30} \mathrm{IJ}$ recruited participants from patient databases of five centres (two paediatric and three adult hospitals) which encompass regional and metropolitan areas in New South Wales, Australia. One of the three adult hospitals had a dedicated age-based transition clinic. Participants were approached by their treating physicians and nurses and provided informed consent to be contacted by IJ via telephone.

\section{Data collection}

The question guide was semistructured and informed by a qualitative systematic review of patients' attitudes and experiences of transition in rheumatology ${ }^{31}$ and discussion among the research team (online supplemental file 1). Questions pursued areas relating to self-management, available and future support networks, current or recent experiences of transition and suggestions for improved transition. Interviews were initially conducted with two researchers present (IJ or DJT) to pilot the interview guide and train IJ (medical student) in interview techniques. DJT $(\mathrm{PhD})$ had prior experience with qualitative research. The interview guide was subsequently revised to include further questions about medication adherence and residential location as a possible barrier.

IJ and DJT conducted face-to-face and telephone interviews from December 2018 to September 2019. Face-toface interviews were conducted in the home, the clinic or the community (eg, library, café) based on the participant's preference. Before initiating each interview, IJ and DJT introduced their role in the study and the research aims to participants as there were no prior relationships established between the investigator and participants prior to study commencement. Written consent was then obtained from participants or their parents if the patient was under 16 years old. Young people and parents were interviewed separately with the exception of one interview conducted with both patient and guardian based on the participant's choice. Recruitment continued until data saturation, when few or no new concepts emerged was achieved. ${ }^{30}$ Field notes were not made and repeat interviews were not undertaken. Interviews were audiorecorded and transcribed verbatim by IJ and CT. The average interview time was $42 \mathrm{~min}$ and $36 \mathrm{~min}$ for patients and caregivers, respectively.

\section{Analysis}

The transcripts were imported into HyperRESEARCH V.4.0.3 (Researchware, USA) to facilitate coding and storage of data. IJ, DJT, AK, AT, CT and KM used thematic analysis to analyse the qualitative data, which is a method that is beneficial in clinical settings as it provides critical insight that is actionable for healthcare professionals. ${ }^{30}$ Investigators IJ and DJT read and coded all transcripts line by line and conceptualised all sections to inductively identify and compare concepts relating to patient and 


\begin{tabular}{|c|c|}
\hline Patient characteristics & n (\%) \\
\hline \multicolumn{2}{|l|}{ Sex } \\
\hline Male & $6(43)$ \\
\hline Female & $8(57)$ \\
\hline \multicolumn{2}{|l|}{ Age group (years) } \\
\hline $14-19$ & $10(71)$ \\
\hline $20-25$ & $4(29)$ \\
\hline \multicolumn{2}{|l|}{ Age at disease diagnosis (years) } \\
\hline $0-5$ & $5(36)$ \\
\hline $6-10$ & $4(29)$ \\
\hline $11-15$ & $5(36)$ \\
\hline \multicolumn{2}{|l|}{ Interview setting } \\
\hline Home & $10(71)$ \\
\hline Community (eg, café) & $3(21)$ \\
\hline Clinic & $1(7)$ \\
\hline \multicolumn{2}{|l|}{ Geographical location } \\
\hline Rural & $3(21)$ \\
\hline Metropolitan & $11(79)$ \\
\hline \multicolumn{2}{|l|}{ Transition stage } \\
\hline Pre-transition & $2(14)$ \\
\hline During transition & $3(21)$ \\
\hline Post-transition & $7(50)$ \\
\hline Not followed up by rheumatology services & $2(14)$ \\
\hline \multicolumn{2}{|l|}{ Rheumatological condition } \\
\hline Juvenile idiopathic arthritis & $8(57)$ \\
\hline Systemic lupus erythematosus & $3(21)$ \\
\hline Familial Mediterranean fever & $1(7)$ \\
\hline Panniculitis & $1(7)$ \\
\hline Sterile multifocal osteomyelitis & $1(7)$ \\
\hline
\end{tabular}

parent perspectives on transition. They grouped similar and recurring concepts into themes and subthemes. The coding framework was discussed among members of the research team (IJ, DJT, AK, DS-G, GM, AT, KM) to ensure the full depth and breadth of data were reflected in the analysis. An analytical framework was developed through a process of analysis and comparisons of concepts to identify conceptual links to create a thematic schema.

\section{Patient and public involvement}

Patients assisted to recruit their parents and vice versa if patients were under 18 years old. Patients did not design, conduct, report or disseminate the study results and were therefore not included as authors.

\section{RESULTS}

In total, 14 young people and 16 parents participated. The participant characteristics are shown in tables 1 and 2. The age of patients ranged from 15 to 23 years, with a
Table 2 Parent characteristics $(n=16)$

\begin{tabular}{lc}
\hline Parent characteristics & n (\%) \\
\hline Sex & \\
Male & $4(25)$ \\
\hline Female & $12(75)$ \\
\hline Age group (years) & \\
$30-39$ & $1(6)$ \\
\hline $40-49$ & $8(50)$ \\
\hline $50-59$ & $6(38)$ \\
\hline Not reported & $1(6)$ \\
\hline Highest level of education & \\
\hline University degree & $6(38)$ \\
\hline Diploma/certificate & $4(25)$ \\
\hline Secondary school & $5(31)$ \\
\hline Not reported & $1(6)$ \\
\hline Interview setting & \\
\hline Home & $12(75)$ \\
\hline Community (eg, café) & $2(12)$ \\
\hline Clinic & $1(6)$ \\
\hline Telephone & $1(6)$ \\
\hline
\end{tabular}

mean of 18.5 years (SD 2.1). Eight patients and 12 parents were women and 3 patients $(21 \%)$ lived in rural areas. The participants had JIA $(n=8)$, SLE $(n=3)$, panniculitis $(\mathrm{n}=1)$, familial Mediterranean fever $(\mathrm{n}=1)$ and sterile multifocal osteomyelitis $(\mathrm{n}=1)$. The average age at diagnosis was 8 years and ranged from 2 to 15 years old. Two had not commenced the transition process, three were undergoing transition and seven had transferred to adult care. Two patients were lost to follow-up at specialty rheumatology services. All interviews were conducted face-toface except for one that was conducted by telephone. Two participating parents were interviewed independently without participation of their child. Fourteen patients contacted did not participate due to family, work or other commitments, and the majority $(71 \%)$ were 18 years or over.

We identified four themes: avoid repeat of past disruptions, encounter a daunting adult environment, establish therapeutic alliances with adult rheumatology providers and negotiate patient autonomy. The themes and subthemes are described below. Illustrative quotations are provided as online supplemental table. A thematic schema illustrating the conceptual relationships between themes is shown in figure 1. The description of the themes in the following section applies to both patients and parents unless otherwise specified.

\section{Avoid repeat of past disruptions}

Maintain disease stability-patients experienced periods of medical instability during the initial stages of disease manifestation and diagnosis. Patients who had not commenced transition feared that clinicians in the 


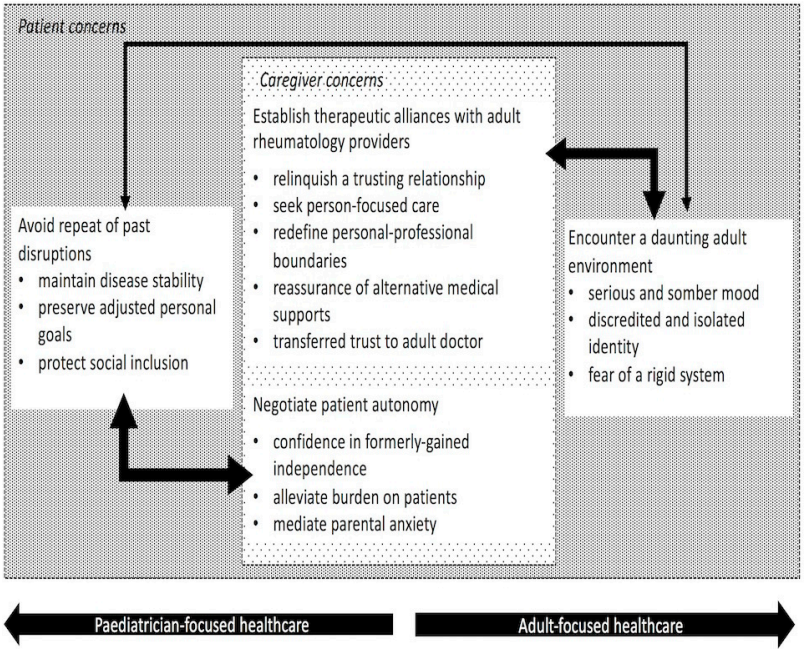

Figure 1 Thematic schema. Parents were concerned about the disease-related aspects of their child's transition. Parents sought to protect their child's social and personal goals by alleviating the disease burden, but simultaneously recognised more autonomy was needed as their child matured. While prior independence encouraged patients' preparedness to maintain disease stability through transition, they were apprehensive that personal goals would be protected. Hence, there was automatic trust in adult providers when transition decisions were led by their paediatrician. Young people and parents hoped to overcome the daunting adult environment by developing a relationship with adult rheumatologists before transfer. However, limited specialist access and adult system rigidities impeded the development of a professional, person-focused alliance.

adult setting would alter their management, which they expected could lead to a repeat of medical instabilities or increased risk of disease flares. During transition, some young adults were confronted by the realisation of longterm nature of their disease, as "[the doctors] always said I would grow out of my arthritis" and felt disconcerted about their 'relian(ce)' on lifelong medications.

Preserve adjusted personal goals-before transition, symptoms of fatigue, low concentration, and absence from school or work impacted patients' ability to pursue educational or vocational goals successfully. This made them feel 'frustrate(ed)' and 'demolished'. Some patients reported being too 'overwhelmed' to continue pursuing 'dreams that (were) crushed'. Other participants learnt to accept the limitations on daily life imposed by their disease, found ways to 'manage and deal' with their bodies' constraints and thereafter, reshaped their ambitions. Patients valued transition timed during periods of disease and personal stability to avoid another disruption having readjusted their career ambitions.

Protect social inclusion-disease stability enabled young people to have 'more time to see friends'. Through transition, they valued support by friends who saw them 'as someone separate from (the disease)' and hence did not feel the need for patient support groups. Parents thought that friends enabled young participants 'to forget what (they were) going through'. However, patients and parents in regional areas, as well as some younger adolescent participants, wanted support groups during transition. They perceived their friends could not 'really understand' them and reported being subtly excluded from social events because friends believed their disease was activity-limiting.

\section{Encounter a daunting adult environment}

Serious and sombre mood-the adult hospital was described as 'gloomy' and dismal, where the warmth and liveliness of the paediatric hospital enabled patients to feel "like I wasn't a patient". Participants perceived 'the white, the windows, people looking around' and physical 'maze'-like layout in adult hospitals to be 'stressful'. The quiet atmosphere and lack of ward activities to entertain patients meant that they had no distractions and felt "put down' from dwelling on their disease symptoms.

Discredited and isolated identity-participants observed that clinicians in the adult healthcare setting were not as 'bubbly' or personable compared with clinicians in the paediatric hospital. In the adult hospital, some reported their 'invisible' symptoms, such as pain, were ignored by healthcare workers. Patients also experienced isolation when surrounded by elderly patients who appeared withdrawn and reluctant to talk with others. From clinicians, being asked about their medical history repeatedly made patients feel insignificant: "It'd be nice if the staff knew [my history] already, and they're just asking [me] to confirm." To protect young people from feeling isolated, some parents believed their involvement was more necessary in the adult environment where they thought patients received less attentive care than in paediatrics. Parents themselves reported feeling like 'outsider(s)' when they were unable to answer questions by adult clinicians who had higher expectations of parental disease knowledge.

Fear of a rigid system-young people anticipated that restricted doctor availability and reduced capacity to reschedule appointments in the adult system would limit their ability to adapt medical appointments around other life priorities. Around the time of transition, parents wanted to be informed beyond medical issues, such as specific requirements needed to attain financial government support, especially when young people were leaving home for tertiary study or vocation.

\section{Establish therapeutic alliances with adult rheumatology providers}

Relinquish a trusting relationship-young participants trusted their paediatric rheumatologist who they described was 'someone who knows you so well' ... and was like 'a second (parent)'. Patients reported their rheumatic condition was a source of insecurity and valued the comfort their paediatric rheumatologist provided them: "I'm quite a confident person but [my disease is] quite a vulnerable side." To leave the care of the paediatric rheumatology was one of the most 'upsetting' aspects of transition. 
Seek person-focused care-young people reported feeling reassured when 'important aspects of (their) life' such as psychological and social concerns were addressed during consultations. They could 'warm up faster' to the adult rheumatologist if they demonstrated interest in personal goals. However, some young adults felt too intimidated to raise medical concerns because they perceived adult rheumatologists to be constantly 'busy'. Given the invisibility of patients' symptoms, such as pain, parents emphasised that clinicians should enquire specifically into patients' well-being. They believed personal issues were often inter-related with presenting medical concerns: "You need a doctor that's interested in the whole picture for [their background] to be helpful... to connect the dots to symptoms coming up" and therefore appreciated continuity of care that was whole personfocused, not just clinical.

Redefine personal-professional boundaries-participants struggled to redefine subtle social-professional boundaries with their adult rheumatologists such as the clinician's flexibility to fill administrative forms between appointments, and leniency towards poor medication adherence. Parents and young people appreciated the accessibility of paediatric rheumatologists to promptly act during flares or answer questions by phone or email and were afraid they would not experience the same level of support from adult rheumatologists.

Reassurance of alternative medical supports-young adults felt 'less trapped' through transition when they had ongoing support from their paediatric rheumatologist and other familiar doctors. A meeting with the adult rheumatologist prior to transfer made transition less 'daunting' and less like 'being thrown into fire'. Transition specialist nurses were also valued in preparing young people and parents for expectations of medication adherence, and expectations of the adult rheumatologist.

Transferred trust to adult doctor-participants were confident in their paediatrician's choices to tailor individualised transition plans and therefore described an automatic confidence in their adult rheumatologist as: "[My paediatrician] would put me in good hands... with someone he knows I'd like." They looked forward to developing a similarly trusting relationship with their new adult rheumatologist. A well-communicated transfer of medical and psychosocial history between rheumatologists hence provided major 'security' and 'comfort' for parents and young people.

\section{Negotiate patient autonomy}

Confidence in formerly gained independence-young people found transition was easy when they had developed independent self-care in the past. Previous experiences such as non-English or minimal English-speaking parents, previous changes in care providers or prior admission to adult wards required greater responsibility from patients to interpret medical information themselves. Some young people compared transition to 'going from school to university'. They were not concerned with medication adherence following transition and in fact, experienced more stress when they did not regularly take their medications. Parents believed that during the period of transition, their child increasingly matured and could react more negatively to parental advice, which they believed warranted less parental care. Parents expected their children to be more independent in medicine taking and honest when they felt unwell.

Alleviate burden on patient-parents believed they had a duty to protect their child from the burden of disease and found it difficult to 'just walk away' from involvement in their child's care. Parents supported their child in other aspects of life such as transportation, housing and costs of treatment: "you might not pay the mortgage this week, but [they'll] get [their] medications." As such, parents continued to be invested in care, despite confidence in their child's ability to manage their health. Some young people appreciated their parents' presence during consultations as they believed they did not 'fully understand' their medical history and struggled with the increased need to 'bring up (their) own concerns'.

Mediate parental anxiety-young people were acutely aware that their parents were anxious about their disease and believed that disease diagnoses and flares were 'more stressful for their parents than it was for (themselves)'. Parents likewise expressed that their main concern was their child's health, such as the inability to identify or predict flare severity and the long-term disease impacts on life expectancy. Hence, young participants, sensitive to their parental anxiety, desired either more or less autonomy during transition. Some patients reported more motivation to manage themselves independently and were less likely to disclose feeling unwell to prevent parental worries. Other patients felt obligated to forfeit their independence so that their parents could feel more reassured through continuing their caregiver role of their child.

\section{DISCUSSION}

Young people perceived that the transition process was an unstable period which could potentially jeopardise their disease stability and personal ambitions. Young people feared that their complex health information would not be comprehensively transferred or communicated between the paediatric and adult healthcare providers. Young people were concerned that adult healthcare providers would not discuss or consider their personal recreational and vocational goals. They perceived the adult healthcare system to be rigid and confronting, and were uncertain that the trust they had with their paediatrician to care for them as a whole person would be developed with their new adult rheumatologist. However, young people felt more confident to maintain their disease stability when they experienced prior independence and had other health professionals, such as their general practitioner, transition nurse or other specialists, available for support. To protect their child's personal and social stability, 
parents wanted to stay involved in their child's care after transition and help alleviate their disease burden. Some young people struggled with the tensions of desiring greater independence and enabling ongoing caregiver involvement to avoid additional parental worry.

There were some differences noted in patient perspectives based on geographical location and age. Young people and families who lived in non-metropolitan areas tended to feel isolated and expected that this could be addressed with the opportunity to join support groups during the transition period. Younger adolescents felt misunderstood and excluded by peers while young adults had been able to form strong relationships with friends, providing a feeling of acceptance and less need for social support groups. Our study included patients with different rheumatic diseases and we found that young people and parent perspectives of transition were consistent across different conditions.

Similar patient perspectives of transition are shown in studies in rheumatology and other life-long conditions such as diabetes mellitus and mental health disorders. It is well established that while young people with life-long conditions accept transition as an inevitable process, they report a hostile adult environment and distress in severing relationships with their trusted paediatric clinician, which are consistent with both our findings and the theoretical Bridges Transitions Framework. ${ }^{102425}{ }^{33-35}$ A recent systematic review noted that young people with diabetes mellitus expected their paediatrician to be a 'bridge' to their adult provider, to discuss expectations in the adult system and to guide them on how to ask questions to their new clinician without feeling like a burden. ${ }^{34}$ We found that patients felt prepared for transition when they had experience in self-management prior to transition and could access other supportive health clinicians including primary care physicians, transition nurses and other specialists.

The need to balance autonomy and dependence on support from family has also been previously identified. ${ }^{36}$ A study in the area of mental health services found that while patients perceived transition as a chance to gain greater independence from parents, they valued continued parental involvement as they lacked knowledge of their own disease diagnoses. ${ }^{37}$ While this has also been recognised in rheumatology-specific conditions, ${ }^{24} 3338$ our findings highlight some tensions. Young people were sensitive that their parents would be anxious if they were uninformed or uninvolved in their child's health. To protect and minimise parental stress, some young people wanted to involve parents in clinical appointments, despite having to forego some level of independence. Different degrees of autonomy sought by young people call for a negotiation in the strategies used to support independent self-management.

We included participants with a range of experiences of transition, and from regional and urban areas to strengthen our purposive sampling, despite relatively small subgroup numbers. We recruited participants until data saturation was achieved and used investigator triangulation (IJ, DJT, AT) to ensure that the findings reflect the full range and depth of the data collected. Triangulation was performed throughout the duration of the study, which allowed for an inductive process of theme analysis and refinement to occur.

However, there are some potential limitations. Inclusion in this study required participants to be English speaking and in Australia, which may therefore limit the transferability of the findings beyond this setting. In addition, the majority of individuals who declined to participate were over 18 years of age, suggesting a possible selection bias. However, we note that similar themes in studies conducted in other populations and settings have been identified. ${ }^{1042533}$ The lack of patient involvement in the study design may limit the clinical relevance and transferability of these findings. However, this study was undertaken to inform a model of transitional care at a tertiary adult and children's hospital in Australia. Furthermore, different pathologies, disease severity and patient stages of transfer may limit the transferability of our findings to other settings, as varied clinical courses and disease manifestations may lead to differing perceptions of transitional support from patients and caregivers. Finally, structured parameters to measure patient outcomes such as the Visual Analogue Scale-global and Health Assessment Questionnaire (HAQ) / Childhood HAQ parameters were not collected during this study.

To improve transition, our findings suggest the need for paediatric rheumatologist-led planning; supporting a consistent management approach; ensuring that patients can readily access medical support from trusted healthcare workers such as primary care physicians, previous paediatric rheumatologists, outpatient rheumatology services and pharmacists when needed; addressing personal and social goals and expectations when building rapport. Given that young people have often built trust with their paediatric rheumatologist, we suggest that paediatricians support gradual transition by referring and introducing young people to the adult healthcare provider and discuss the differences in expectations in adult care with patients and families prior to meeting the adult provider. Maintaining a consistent approach to medical management (ie, avoiding changes to treatment) initially after transfer to adult healthcare may reduce the anxiety of parents regarding disease instability and increase young people' comfort in developing rapport with their adult rheumatologist. Age-specific transition clinics are consistently suggested to reduce the perceived differences between paediatric and adult care cultures for young people with life-long conditions. ${ }^{34} 35$

Patient support groups have been previously shown to improve social well-being and optimism in transitioning patients. ${ }^{10} 2533$ 39-43 While patients in our study agreed that peer groups could be desirable in periods of disease instability or uncertain diagnoses, patients wanted to be more informed about medical support services (eg, general practitioners, allied health, transition nurses) 
Box 1 Suggestions for caring for patients with

rheumatological conditions transitioning to adult

healthcare

Before transfer

- Discuss needs for autonomy with patients and caregivers early in the transition process.

- Discuss different expectations in the adult system with patients and families prior to meeting the adult provider.

- Promote paediatrician-led transition planning that involves referral and introductions to a trusted adult provider.

During transfer

- Group appointments with young people by age in adult centres.

- Seek more time during initial appointments to build rapport with patient by discussing personal and career goals prior to medical goals, in both paediatric and adult settings.

- If possible, avoid changing treatment initially after transfer.

After transfer and throughout transition

- Clarify and support individualised goals for self-management including access to care.

- Provide information on medical support services (eg, primary care physicians, allied health, transition nurses) available for patients and families.

and transition-related information sources they could access (eg, websites, apps). Training clinicians involved in the care of patients transitioning to adult rheumatology services is needed to ensure that their priorities and needs are met. ${ }^{3}$ This reflects findings from a Delphi study, conducted to develop a set of minimum training requirements for adult rheumatologists, which identified high priority areas for rapport building: training in issues unique to transition and adolescence, and relevant referral services that can be readily accessed by patients. ${ }^{44} 45$ Suggestions for caring for patients with rheumatological conditions undergoing transition are outlined in box 1 , and are organised sequentially by stages of transfer as to reflect the continuum of phases in the Bridges Transitions Framework.

While patient perspectives are used to evaluate existing models of care,$^{34} 46$ few inform the design of transition interventions. ${ }^{6} 254748$ A transition model that is co-designed can help to ensure that the patient needs are considered and addressed. ${ }^{48}$ For example, patient navigator programmes may have potential in the context of transition. Patient navigators are trained non-medical or medical personnel, who assist young people with lifelong conditions through different care settings to understand clinical decisions and overcome barriers to access. ${ }^{49}$ Studies suggest that navigator programmes may help to improve adherence to initial treatment, medical surveillance, quality of life and access to care as well as reduce drop-out rates from adult care.$^{50-55}$

High-quality evidence of the effectiveness of transition interventions is lacking and most trials in this area are underpowered and short term. ${ }^{56}$ Further, intervention efforts have mainly targeted transition preparation more so than young people needs after the transfer to adult care. $^{57}$ Trials involving transition coordinators have shown improvement in clinic attendance rates and reduced acute complications in patients with type 1 diabetes mellitus. ${ }^{34559}$ Preliminary and single-centre evaluations have also been performed in rheumatology. ${ }^{55} 60$ We suggest that trials to evaluate models of care involving transition coordinators may be an area of future research.

\section{CONCLUSIONS}

Patients and parents perceive transition as a challenging and vulnerable period which may threaten medical, educational or psychosocial goals. Young people with rheumatological conditions in particular want stability, given the unpredictable disease activity. The unique set of patient symptoms can often be under-recognised in rheumatic diseases, heightening parental worries in being able to recognise flares, and inhibiting therapeutic alliances being formed with healthcare workers in the adult setting. Transition interventions that involve ongoing paediatrician support, negotiated autonomy in self-management including accessing care, and consistent management approaches between providers are needed, to improve life-participation and quality-of-life outcomes in young people with inflammatory rheumatic diseases.

\section{Author affiliations}

${ }^{1}$ Sydney School of Public Health, The University of Sydney, Sydney, New South Wales, Australia

${ }^{2}$ Centre for Kidney Research, Children's Hospital at Westmead, Westmead, New South Wales, Australia

${ }^{3}$ Faculty of Medicine, University of New South Wales, Sydney, New South Wales, Australia

${ }^{4}$ Department of Rheumatology, Bone and Joint Centre, Royal Newcastle Centre, John Hunter Hospital, Newcastle, New South Wales, Australia

${ }^{5}$ School of Medicine and Public Health, The University of Newcastle Faculty of Health and Medicine, Callaghan, New South Wales, Australia

${ }^{6}$ Department of Rheumatology, Liverpool Hospital, Liverpool, New South Wales, Australia

${ }^{7}$ Department of Rheumatology, The Sydney Children's Hospitals Network Randwick and Westmead, Westmead, New South Wales, Australia

${ }^{8}$ Rheumatology, Canberra Rheumatology, Canberra City, Australian Capital Territory, Australia

${ }^{9}$ College of Health and Medicine, Australian National University Medical School, Canberra, Australian Capital Territory, Australia

${ }^{10}$ Ingham Institute for Applied Medical Research, Liverpool, New South Wales, Australia

${ }^{11}$ Department of Rheumatology, Prince of Wales Hospital and Community Health Services, Randwick, New South Wales, Australia

${ }^{12} \mathrm{~S} c h$ ool of Public Health, The University of Sydney, Camperdown, New South Wales, Australia

${ }^{13}$ Global Health and Development, London School of Hygiene and Tropical Medicine Faculty of Public Health and Policy, London, UK

${ }^{14}$ University of Sydney, Sydney School of Public Health, New South Wales Ministry of Health, Sydney, New South Wales, Australia

Twitter Karine Manera @KarineManera, Allison Tong @allisontong1 and David J Tunnicliffe @djtunnicliffe

Acknowledgements The authors thank all participants for their contribution to this study.

Contributors IJ was involved in the data collection and analysis, drafting and revision of the manuscript. GM, DS-G, FN, JC, SO, GH and AD substantially contributed to the conception and design as well as the manuscript revisions. CT, 
AK, KM and SB analysed, interpreted the data and revised the manuscript. AT and DJT were involved in the conception, design, analysis, drafting and revision of the manuscript. All authors read and approved the final manuscript and agree to be accountable for all aspects of the work related to the accuracy and integrity.

Funding This project was funded by the HJ \& GJ McKenzie Grant as part of the 2018 Arthritis Australia National Research Program. IJ was supported by the Sydney Medical School Summer Research Scholarship 2018-2019.

Competing interests None declared.

Patient consent for publication Not required.

Ethics approval Ethics approval for all five sites was obtained from the Sydney Children's Hospital Network (LNR/18/SCHN/395) on 6th November 2018 as well as site-specific approval from each site: The Sydney Children's Hospital Network Research Ethics Office (LNRSSA/18/SCHN/396), Hunter New England Research Ethics \& Governance Office (SSA/18/HNE/300), Research and Ethics Office South Western Sydney Local Health District (SWSLHD (LNRSSA/18/LP00L/532), South Eastern Sydney Local Health District (SESLHD) Research Support Office (19/G/033).

Provenance and peer review Not commissioned; externally peer reviewed.

Data availability statement Data are available upon reasonable request. The datasets used and/or analysed during the current study are available from the corresponding author on reasonable request.

Supplemental material This content has been supplied by the author(s). It has not been vetted by BMJ Publishing Group Limited (BMJ) and may not have been peer-reviewed. Any opinions or recommendations discussed are solely those of the author(s) and are not endorsed by BMJ. BMJ disclaims all liability and responsibility arising from any reliance placed on the content. Where the content includes any translated material, BMJ does not warrant the accuracy and reliability of the translations (including but not limited to local regulations, clinical guidelines, terminology, drug names and drug dosages), and is not responsible for any error and/or omissions arising from translation and adaptation or otherwise.

Open access This is an open access article distributed in accordance with the Creative Commons Attribution Non Commercial (CC BY-NC 4.0) license, which permits others to distribute, remix, adapt, build upon this work non-commercially, and license their derivative works on different terms, provided the original work is properly cited, appropriate credit is given, any changes made indicated, and the use is non-commercial. See: http://creativecommons.org/licenses/by-nc/4.0/.

\section{ORCID iDs}

Ivy Jiang http://orcid.org/0000-0002-5351-1192

Ayano Kelly http://orcid.org/0000-0003-3325-3840

Karine Manera http://orcid.org/0000-0002-0552-6074

\section{REFERENCES}

1 Hersh A, von Scheven E, Yelin E. Adult outcomes of childhood-onset rheumatic diseases. Nat Rev Rheumatol 2011;7:290-5.

2 Hazel E, Zhang X, Duffy CM, et al. High rates of unsuccessful transfer to adult care among young adults with juvenile idiopathic arthritis. Pediatr Rheumatol Online J 2010;8:2

3 Sadun RE, Schanberg LE. Transition and transfer of the patient with paediatric-onset lupus: a practical approach for paediatric and adult rheumatology practices. Lupus Sci Med 2018;5:e000282.

4 Moorthy LN, Peterson MG, Hassett AL, et al. Burden of childhoodonset arthritis. Pediatr Rheumatol Online J 2010;8:20.

5 Bertilsson L, Andersson-Gäre B, Fasth A, et al. Disease course, outcome, and predictors of outcome in a population-based juvenile chronic arthritis cohort followed for 17 years. J Rheumatol 2013;40:715-24.

6 Robertson LP, McDonagh JE, Southwood TR, et al. Growing up and moving on. A multicentre UK audit of the transfer of adolescents with juvenile idiopathic arthritis from paediatric to adult centred care. Ann Rheum Dis 2006;65:74-80.

7 Tucker LB, Cabral DA. Transition of the adolescent patient with rheumatic disease: issues to consider. Pediatr Clin North Am 2005;52:641-52.

8 McDonagh JE. Young people first, juvenile idiopathic arthritis second: transitional care in rheumatology. Arthritis Rheum 2008;59:1162-70.

9 Eleftheriou D, Isenberg DA, Wedderburn LR, et al. The coming of age of adolescent rheumatology. Nat Rev Rheumatol 2014;10:187-93.

10 Östlie IL, Dale Öystein, Möller A. From childhood to adult life with juvenile idiopathic arthritis (JIA): a pilot study. Disabil Rehabil 2007;29:445-52.
11 Zisman D, Samad A, Ardoin SP, et al. US Adult Rheumatologists' Perspectives on the Transition Process for Young Adults With Rheumatic Conditions. Arthritis Care Res 2020;72:432-40.

12 Michaud P-A, Schrier L, Ross-Russel R, et al. Paediatric departments need to improve residents' training in adolescent medicine and health: a position paper of the European Academy of Paediatrics. Eur J Pediatr 2018;177:479-87.

13 Bridges W. Managing transitions : making the most of change. 4th edn. Boston, MA: Da Capo Lifelong Books, A Member of the Perseus Books Group, 2016.

14 Tong A, Jones J, Speerin R, et al. Consumer perspectives on pediatric rheumatology care and service delivery: a qualitative study. J Clin Rheumatol 2013;19:234-40.

15 Cruikshank M, Foster HE, Stewart J, et al. Transitional care in clinical networks for young people with juvenile idiopathic arthritis: current situation and challenges. Clin Rheumatol 2016;35:893-9.

16 Shaw KL, Southwood TR, McDonagh JE. Transitional care for adolescents with juvenile idiopathic arthritis: a Delphi study. Rheumatology 2004;43:1000-6.

17 Raunsbæk Knudsen L, de Thurah A, Bjerrum M. Transition from child to adult care in an outpatient clinic for adolescents with juvenile idiopathic arthritis: an inductive qualitative study. Nurs Open 2018:5:546-54.

18 O'Sullivan G, O'Higgins S, Caes L, et al. Self-management needs of Irish adolescents with juvenile idiopathic arthritis (JIA): how can a Canadian web-based programme meet these needs? Pediatr Rheumatol Online J 2018;16:68.

19 Nguyen T, Embrett MG, Barr NG, et al. Preventing youth from falling through the cracks between Child/Adolescent and adult mental health services: a systematic review of models of care. Community Ment Health J 2017;53:375-82.

20 Lugasi T, Achille M, Stevenson M. Patients' perspective on factors that facilitate transition from child-centered to adult-centered health care: a theory integrated metasummary of quantitative and qualitative studies. J Adolesc Health 2011;48:429-40.

21 Colver A, McConachie H, Le Couteur A, et al. A longitudinal, observational study of the features of transitional healthcare associated with better outcomes for young people with long-term conditions. BMC Med 2018;16:111.

22 Heath G, Farre A, Shaw K. Parenting a child with chronic illness as they transition into adulthood: a systematic review and thematic synthesis of parents' experiences. Patient Educ Couns 2017;100:76-92.

23 Suris J-C, Larbre J-P, Hofer M, et al. Transition from paediatric to adult care: what makes it easier for parents? Child Care Health Dev 2017;43:152-5.

24 Howland S, Fisher K. Looking through the patient lens - improving best practice for young people with juvenile idiopathic arthritis transitioning into adult care. Springerplus 2015;4:111-11.

25 Hilderson D, Moons P, Van der Elst K, et al. The clinical impact of a brief transition programme for young people with juvenile idiopathic arthritis: results of the DON'T RETARD project. Rheumatology 2016;55:133-42

26 Knight A, Vickery M, Fiks AG, et al. The illness experience of youth with lupus/mixed connective tissue disease: a mixed methods analysis of patient and parent perspectives. Lupus 2016;25:1028-39.

27 van Staa AL, Jedeloo S, van Meeteren J, et al. Crossing the transition chasm: experiences and recommendations for improving transitional care of young adults, parents and providers. Child Care Health Dev 2011;37:821-32.

28 Tong A, Sainsbury P, Craig J. Consolidated criteria for reporting qualitative research (COREQ): a 32-item checklist for interviews and focus groups. Int J Qual Health Care 2007;19:349-57.

29 Palinkas LA, Horwitz SM, Green CA, et al. Purposeful sampling for qualitative data collection and analysis in mixed method implementation research. Adm Policy Ment Health 2015;42:533-44.

30 Liamputtong P. Qualitative research methods. 4th edn. South Melbourne: Oxford University Press, 2013.

31 Kelly A, Niddrie F, Tunnicliffe D. Patients' attitudes and experiences of transition from paediatric to adult healthcare in rheumatology: a qualitative systematic review. Rheumatology 2020.

32 Saunders B, Sim J, Kingstone T, et al. Saturation in qualitative research: exploring its conceptualization and operationalization. Qual Quant 2018;52:1893-907.

33 Applebaum MA, Lawson EF, von Scheven E. Perception of transition readiness and preferences for use of technology in transition programs: teens' ideas for the future. Int J Adolesc Med Health 2013;25:119-25.

34 Crowley R, Wolfe I, Lock K, et al. Improving the transition between paediatric and adult healthcare: a systematic review. Arch Dis Child 2011:96:548-53. 
35 Coyne I, Sheehan AM, Heery E, et al. Improving transition to adult healthcare for young people with cystic fibrosis: a systematic review. J Child Health Care 2017;21:312-30.

36 Kaufman $\mathrm{H}$, Horricks L, Kaufman M. Ethical considerations in transition. Int J Adolesc Med Health 2010;22:453-9.

37 Broad KL, Sandhu VK, Sunderji N, et al. Youth experiences of transition from child mental health services to adult mental health services: a qualitative thematic synthesis. BMC Psychiatry 2017; $17: 380$

38 Findley MK, Cha E, Wong E, et al. A systematic review of transitional care for emerging adults with diabetes. J Pediatr Nurs 2015;30:e47-62.

39 Tunnicliffe DJ, Singh-Grewal D, Chaitow J, et al. Lupus means sacrifices: perspectives of adolescents and young adults with systemic lupus erythematosus. Arthritis Care Res 2016;68:828-37.

40 Lindsay S, Smith S, Bellaby P, et al. The health impact of an online heart disease support group: a comparison of moderated versus unmoderated support. Health Educ Res 2009;24:646-54.

41 Ahola Kohut S, Stinson J, Forgeron P, et al. A qualitative content analysis of peer mentoring video calls in adolescents with chronic illness. J Health Psychol 2018;23:788-99.

42 Carr R, Whiteson M, Edwards M, et al. Young adult cancer services in the UK: the journey to a national network. Clin Med 2013;13:258-62.

43 Smith WR, Sisler IY, Johnson S, et al. Lessons learned from building a pediatric-to-adult sickle cell transition program. South Med J 2019;112:190-7.

44 McDonagh JE, Southwood TR, Shaw KL. Unmet education and training needs of rheumatology health professionals in adolescent health and transitional care. Rheumatology 2004;43:737-43.

45 Calvo I, Antón J, Bustabad S, et al. Consensus of the Spanish Society of pediatric rheumatology for transition management from pediatric to adult care in rheumatic patients with childhood onset. Rheumatol Int 2015;35:1615-24.

46 Clemente D, Leon L, Foster H, et al. Systematic review and critical appraisal of transitional care programmes in rheumatology. Semin Arthritis Rheum 2016;46:372-9.

47 McDonagh JE, Southwood TR, Shaw KL, et al. The impact of a coordinated transitional care programme on adolescents with juvenile idiopathic arthritis. Rheumatology 2007;46:161-8.

48 Bate P, Robert G. Experience-Based design: from redesigning the system around the patient to co-designing services with the patient. Qual Saf Health Care 2006;15:307-10.
49 van Zwieten A, Caldwell P, Howard K, et al. NAV-KIDS2 trial: protocol for a multi-centre, staggered randomised controlled trial of a patient navigator intervention in children with chronic kidney disease. BMC Nephrol 2019;20:134.

50 Robinson-White S, Conroy B, Slavish KH. Patient navigation in breast cancer: a systematic review. Cancer Nurs 2010;33:127-40.

51 McBrien KA, Ivers N, Barnieh L, et al. Patient navigators for people with chronic disease: a systematic review. PLoS One 2018:13:e0191980.

52 Benz Scott L, Gravely S, Sexton TR, et al. Effect of patient navigation on enrollment in cardiac rehabilitation. JAMA Intern Med 2013:173:244-6.

53 Ali-Faisal SF, Benz Scott L, Johnston L, et al. Cardiac rehabilitation referral and enrolment across an academic health sciences centre with eReferral and peer navigation: a randomised controlled pilot trial. BMJ Open 2016;6:e010214.

54 Van Walleghem N, Macdonald CA, Dean HJ. Evaluation of a systems navigator model for transition from pediatric to adult care for young adults with type 1 diabetes. Diabetes Care 2008;31:1529-30.

55 Jensen PT, Karnes J, Jones K, et al. Quantitative evaluation of a pediatric rheumatology transition program. Pediatr Rheumatol Online $J$ 2015:13:17.

56 Campbell F, Biggs K, Aldiss SK, et al. Transition of care for adolescents from paediatric services to adult health services. Cochrane Database Syst Rev 2016;3.

57 Hart LC, Patel-Nguyen SV, Merkley MG, et al. An evidence map for interventions addressing transition from pediatric to adult care: a systematic review of systematic reviews. J Pediatr Nurs 2019;48:18-34.

58 Cadario F, Prodam F, Bellone S, et al. Transition process of patients with type 1 diabetes (T1DM) from paediatric to the adult health care service: a hospital-based approach. Clin Endocrinol 2009;71:346-50.

59 Steinbeck KS, Shrewsbury VA, Harvey V, et al. A pilot randomized controlled trial of a post-discharge program to support emerging adults with type 1 diabetes mellitus transition from pediatric to adult care. Pediatr Diabetes 2015;16:634-9.

60 McDonagh JE, Shaw KL, Southwood TR. Growing up and moving on in rheumatology: development and preliminary evaluation of a transitional care programme for a multicentre cohort of adolescents with juvenile idiopathic arthritis. $J$ Child Health Care 2006;10:22-42. 